\title{
Exploration and Application of Modern Color Concept
}

\author{
Qingbo ZHANG \\ Art \&Design Department, Harbin University, Harbin China \\ Yu GAO \\ Heilongjiang Forest Protection Institute, Harbin China
}

\begin{abstract}
Color is one of the basic subjects in art teaching, including objective description and subjective expression. The essence of art lies in the transcendence for real life. In view of the art teaching in college, the color should break away from the initial stage in which the objective reality is simply portrayed and get rid of the subordinate position of depicted objects. The factors such as ethnic group, religion and age should be considered. Through the teaching, students can easily control the color, tap its symbolic meaning, emphasize the emotional expression, cultivate the display of personality and express the true experience for nature and life. Then, the significance of color can be highlighted and it will eventually become the independent visual expression element.
\end{abstract}

KEYWORD: color; aesthetic factors; symbolic meaning; emotional expression

\section{OPTICAL PROPERTIES OF COLOR}

The research of color is based on the emergence and the development of optics. The lights with different wavelengths can cause the different color perceptions. Therefore, different light sources have different colors. The light receiving members exhibit different colors according to light absorption and reflection capacity. For the basic concepts such as hue, purity, brightness, binary color, compound color, complementary color law, intermediate color law and substitution rate, the theoretical understanding is very important for practical application. The color performance can follow some basic rules, such as the deployment methods of light color, natural color, ambient color, color perspective and colors. The understanding of the color performance from the aspect of science is the transition from stylized training to understanding and acceptance, which is the basic training objective of color teaching in college and that can lay the foundation for future creation. After understanding the scientific principles of colors, our vision will be more open.

$80 \%$ of human perception of outside world come from eyes and color can give people the strongest visual impact. There are some scientific explanations and analysis for colors, but no one can explain all color phenomena in nature. These explanations are almost useless for artists. The artists are associated with colors in emotion and they can use the visual art language to interpret colors. "In today's Western
Academy of Fine Arts, teachers may think the students who advocate painting outdoors are not normal. In China, color paintings are recognized as the weak link in art institutions. Even for some wellknown painters, their paintings produced in meditation under the influence of Impressionist colors just present the vague sense of color that is similar to the Impressionist colors. There exists the Impressionist color surface, but without the heightened senses for color. Therefore, the artist's works clearly reveal the false and pale senses." ${ }^{[1]}$ If the color is just taught according to theory, the painting will become a program.

\section{FACTORS TO INFLUENCE THE COLOR AESTHETIC UNDERSTANDING}

The color is closely related to the society just like the humans. The history of a color is the history of society in first. It is society that creates the color, give meanings to color, find its function and determine whether it is feasible. The topics related with color are actually the topics related with society. The choice of color for people is not random, which is subject to ethnic groups, religion, age, region, folklore, ethics and other factors.

\subsection{Ethnic factor}

As a social phenomenon, the members of ethnic groups have some commonalities in living habits, 
cultural traditions, psychology and emotions, etc. This fact determines that the same ethnic people have some similar culture and psychological state to some extent and they can show the common aesthetic taste. This commonality can present the unique national style and national manner in colors. For example, blue and white were popular in Yuan Dynasty. "They are born by blue wolf and white deer." (the first volume of "Secret History of Mongolia"). Mongolians believe that their ancestors have blue and white colors. White is the color of good luck and black has the evil meaning. Disgust of black is the tradition of northern steppe shamanism. In ancient times, black was advocated in Xia Dynasty.

\subsection{Religious factor}

Religion significantly influences art, especially for the ancient works, it is obvious to reflect that they are served for religion. In Medieval paintings, the color is solemn, which can map out the cold, gloomy and dull temperament under Christian influence. Islam has no idolatry and their paintings are mostly the auxiliaries of buildings. The harassment plant patterns and the brilliant colors are considered as the theme. Islam, especially the Shiah, advocates green. Therefore, when learning and studying the paintings, the understanding of religious factors is helpful to deepen our understanding for work styles.

\subsection{Age factor}

The same color has the different degrees of preference in different historical periods. Research shows that blue is the most popular color in western at present, followed by green (less than $20 \%$ ), white and red (8\% each). However, in ancient Europe, compared with other colors, blue is looked down upon. It can not distinct the grades and the religious rituals. Even in Roman times, blue is a symbol of ignorance. In Middle Ages, blue is a noble color, which represents the loyalty and promotes people to remind the beautiful sky and the holy soul. Christ and Virgin are dressed in blue and red robes. In the $18^{\text {th }}$ century, blue is a magnificent transition, which becomes Europe's favorite and that is a symbol of technology and rationality. In Goethe's "Sorrows of Young Werther", the young Werther has a blue jacket that is unwilling to discard. Blue becomes a popular color of clothing. Blue has represented love, depression and dreams.

People in different times have different aesthetic senses under the influence and the constraints of particular social practice and social thoughts. The creative styles and the aesthetic taste will exhibit the characteristics of age under the domination of such aesthetic sense. The understanding of the color preferences of people in different times is helpful to understand the basic principles of color use of painters, deepen the understanding and the perception of different styles shown in paintings in different times and enrich the language performance in paintings.

\section{SYMBOLISM OF COLORS}

In 1676, Newton used a prism to refract the sunlight, which provided the basis for color from a scientific point of view. Color does not exist alone in nature. The color will appear because of lights. Goethe, Hegel and other aestheticians all emphasized the emotional features and the spiritual characteristics of color. Goethe advocated the host and guest bi-color perception of humans, "anything exists outside exists our mental state at the same time; the eyes and the outside world have their own colors." ${ }^{[2]}$ Hegel believed that "the sense of color should be a unique quality of artists, which is an ability for them to grasp colors and design colors; therefore, it is a basic factor in the reproduction of imagination and creativity." ${ }^{[3]}$ Compared with other elements in painting, color has more spiritual and aesthetic values. People can often feel the psychological cues and the influence of colors.

Founded in 1920s and 1930s, Bauhaus is a modern art school that has a critical impact on the development of modern art education. At the beginning of establishment, the color has been set as a compulsory course in Bauhaus. In addition to teaching basic theory, a number of masters such as Eaton, Klee and Kandinsky have applied the strict rational thinking in the essence of visual experience and art creativity. They were more concerned with the emotional features and the spiritual characteristics of color rather than the scientific nature of color. They emphasized the association and the symbolism of colors. The three masters believed that color was associated with graphics and they thought that "square symbolizes peaceful death, black, darkness and red; triangle represents warm, vitality, white and yellow; round symbolizes uniformity, eternity and quietness; moreover, round also represents blue." ${ }^{[4]}$

Kandinsky is an artist who can fully demonstrate the color imagination in modern art. He can transform the art forms of colors in music art. "The yellow is strongly close to more lively color, which can produce unbearable strength and height for eyes and spirit; at this time, the increased sounds are similar to the loud tweeter sound or the tone of bugle in the high scale." ${ }^{[5]}$ The paintings of Kandinsky developed to express the color symbolism from imitating the external color perception and presenting the color emotions.

In the color courses which takes the realistic language as the basis, the color is attached to 
objectivity. Through the simple induction, the still life is depicted in flatten color lump, emphasizing the observation and the performance of lightness, purity, warm color and cold color between color lumps. However, in the modern training which takes the modernist painting language as the basis, the color gradually gets rid of the subordination position of depicted object from sketching to abstract expression. Its own significance has been highlighted and it eventually becomes the independent visual expression element. In view of color teaching in college, it is required to guide the students to induce an object into the abstract color lump in the figurative images. It is independent on the painting in some form. The students should completely break away from the objects considered as color carriers and they should enter into the practice of subjective understanding and expression of pure colors from the emotional color sketching practice. Simplifying the realistic depiction of objects and emphasizing the color beauty of objects as well as the overall relationship with other colors in plane are the keys to change from realistic painting context to modern painting context.

Color can also produce synesthesia, which is linked with the taste sense. For example, people can remind of lemon from yellow and they can remind of green grapes from green and have the sour taste. The warm color and the cold color are also associated with the perception of people.

\section{EMPHASIZING THE EXPRESSION OF COLOR EMOTIONS}

The essence of art lies in the transcendence for real life. Although color is based on objective things, it does not stick to the objective performance. Just as art always pursues ideal, transcendence and freedom. Hegel has discussed some aspects about the essence and the features of art beauty, one of which referred to "organic unity of sensibility and rationality". He once regarded the sensual images of art as eyes and considered the rational images as the soul reflected from eyes. He believed that the soul dominated the eyes and the eyes existed for soul. The phenomenon that the color is employed to objectively and truly reproduce the depicted objected belongs to the initial stage of art teaching. It is required to explore the subjective emotional performance of students in color teaching in college.

According to genders and ages, the responses of people for colors are different. The perception of color is a physiological response for people. However, due to the continuous accumulation of life experience and the relevant experience for colors, people have a certain psychological association for certain colors. Then, the colors will be objectively or subjectively endowed some emotional significance.
"Green skirt is remembered and grasses are pitied everywhere". The emotional feature of color is related to the human mental activities. Due to the different social experience and the cultural cultivation among people, the mental activities are also different. The same person will have the different response for the same objective things under different mental state, which is same as the color emotions. Therefore, the color emotions do not have the strict correspondence and the general emotional attributes are conventional. Although people have different color emotions, there also exists the common point, such as the feelings for warm color and cold color, light color and dark color, distal color and advancing color.

Impressionist painter Manet clearly pointed out that "color is totally a problem of fun and emotion."[6] Based on the traditional light and shade colors and the personality perception of dynamic colors, some color masters after Impressionist can consciously display the emotional color through the cue from oriental colors. The display of the inner feelings of color stimulated by natural color emotions is the consensus of contemporary artists.

Danner thought that the imitation could not produce beauty. Painting needs originality and the phenomenon that the visual organs get enjoyment is the premise and the foundation of exiting of art works. Painting is a special spiritual production, which requires the artists to have keen feeling, rich emotion and vivid artistic imagination. At the same time, the subjective factors of artists should be penetrated into painting and the visual expression as well as impact should be expanded. The reason why Van Gogh's paintings are touching is that his life is devoted to the emotional color performance. From the lemon yellow with little pearl gray to the dark ocher, the non-uniform dark color expresses his "cries of pain". In the torrent of color emotions, his color is very natural and pure. Van Gogh has repeatedly painted his bedroom: lavender walls, floors with red bricks, green windows, creamcolored wooden beds and chairs, red blankets, green lemon pillows, orange dressing table and blue basin. These is no shadow lines in painting except the flat painted color. The complementary colors are mutually reinforced because of the conflicting nature so that the painting has a simple and serene nature. Perhaps Van Gogh let his mind and his thinking rest in this small bedroom.

"For a good color painter, it is not because he would mix color and create color, but because he can use the color levels and unite the levels together. The color will be meaningful if it becomes form. The contemporary artists oppose to pave the beautiful colors to the painting without considering the form relationships of each color. They strive to organize the colors so as to make the form have the highest meaning. This is one of the strengths of 
contemporary artists."[7] In teaching process, teachers should guide the students to consciously express emotions through the transformation means of theme and composition, color and pattern, line surface and texture, light and shadow. The painting shows the re-cognitive subjective artistic feelings of students. The so-called natural phenomenon must be changed into a whole new thing. In creation, each inherent part must serve the overall aesthetic effect of painting. When the students are able to demonstrate their own "images" with color language, their own emotional cohesion will be truly formed. This perceived color is the soul of work. The color teaching in college should not simply describe the objective reality, but should express more life experience for nature and life.

The task of education is not only to teach the students some practical knowledge and necessary abilities, but also to promote the development of personality. In this case, the current education is not only to pursue the practical target, but also to emphasize the spiritual development. The human survival depends on two basic conditions: our actual activities ensure the material demands and our mental imagery provides the creation conditions. Painting is the vivid display of individuality, instead of copying the fixed principles and the stiff modes. The color expression in painting is the personal sensitive response as well as the emotional interpretation. Painting is a passionate act. For color teaching, the most important thing is to teach the students to easily master the color. The color should not dominate the students. The language expression space of color is infinite. It is required to activate and sublime the expression emotion and the creative thinking of color in order to make the works full of vitality and imagination, which should become the expression and exploration target of color teaching in college.

\section{ACKNOWLEDGEMENTS}

This paper is one of the initial results of Humanities and Social Sciences Project of Heilongjiang Department of Education in 2012, namely "Exploration and Application of Modern Color Concept" (project number: 12524076)

\section{REFERENCES}

[1] Li Guangyuan. Color Art. Harbin: Heilongjiang Fine Arts Publishing House Press, 2000: 217.

[2] [Germany] Ekman. Gesprache mit Goethe. Beijing: People's Literature Publishing House Press, 1978: 115.

[3] Hegel. The Third Volume of Aesthetics. Beijing: Commercial Press, 1981: 282.

[4] [Britain]Frank Whitford. Bauhaus. Beijing: SDX Joint Publishing Press, 2002: 110.

[5] [Russia] Kandinsky. Art Spirit. Beijing: China Renmin University Press, 2004: 71.

[6] [U.S.A] Cook. Translated by Du Dingyu. Painting Techniques of Western Painters. Beijing: People's Fine Arts Publishing House, 1981: 74.

[7] [Britain] Clive Bell. Art. Beijing: China Federation of Literature Publishing House, 1985: 161. 